\title{
Microdetermination of Dihydroxyacetone in Biological Fluids
}

\author{
M. U. TSAO AND E. L. SCHWARTZ \\ From the Department of Pediatrics and Communicable Diseases, \\ University of Michigan Medical School, Ann Arbor, Michigan
}

Received September 27, 1960

\section{INTRODUCTION}

In spite of the numerous color reactions described for dihydroxyacetone and other trioses, there are only a few procedures reported for the determination of dihydroxyacetone in biological fluids. Among these procedures, the colorimetric or titrimetric methods seemed feasible for micro adaptation. However, Rabinowitch has shown the discrepancy of the early methods (1-3). Other colorimetric or titrimetric methods (4-6) based on the nonspecific reducing property of dihydroxyacetone also are unsatisfactory for the simple reason that an arbitrary blank is, or should be, included for the calculation. Since this triose cannot be quantitatively converted into pyruvaldehyde (7), the more sensitive and specific procedures for the latter cannot be utilized. A relatively specific method for the determination of low concentrations of dihydroxyacetone in biological fluids from small animals was needed for a metabolic study after administration of this substance. The procedure described in this paper has been developed to meet this need and has been satisfactory in our hands.

The blood is deproteinized with sulfosalicylic acid. The filtrate or a urine sample, after adjustment of $\mathrm{pH}$, is incubated in a buffered glucose oxidase solution. The product is allowed to react with 2,4-dinitrophenylhydrazinc. The excess reagent is removed by the addition of pyruvic acid and partition in benzene-sodium bicarbonate solution. The benzene layer containing the osazone of dihydroxyacetone is washed with sodium bicarbonate solution to remove the hydrazonc of pyruvic acid. After benzene is removed by evaporation, the residue is taken up in alcoholic sodium hydroxide, and the resultant color is read. Since dihydroxyacetone is easily destroyed by strong alkali, interfering chromogens when present can be measured and subtracted from the results by running a sample or filtrate treated with alkali after the incubation with glucose oxidase. 


\section{REAGENTS}

Sulfosalicylic Acid. A $3 \%$ solution prepared once every 2 weeks from AR grade (Mallinckrodt).

Glucose Oxidase Mixture. Prepared by mixing $0.5 \mathrm{gm}$ glucose oxidase (Sigma Chemical Co.), in $5 \mathrm{ml}$ water, $2.5 \mathrm{ml}$ of $2.5 \mathrm{M}$ phosphate buffer, $\mathrm{pH} 6.0$, and $2.5 \mathrm{ml}$ of $0.4 \%$ disodium ethylenediamine tetraacetate (Eastman Kodak) solution.

Metaphosphoric Acid. A $10 \%$ solution prepared fresh weekly.

2,4-Dinitrophenylhydrazine. 2,4-Dinitrophenylhydrazine (Eastman Kodak) is dissolved in hot $2 \mathrm{~N}$ alcoholic $\mathrm{HCl}$. The crystals of the hydrochloride are recrystallized three times, dried in a desiccator, and kept refrigerated. A solution is prepared fresh weekly by shaking $100 \mathrm{mg}$ of the hydrochloride in $20 \mathrm{ml}$ of $2 \mathrm{~N} \mathrm{HCl}$ and filtering.

Pyruvic Acid. Pyruvic acid (Paragon) is distilled under reduced pressure two or more times until crystalline material is obtained in the icechilled receiver. A $2 \%$ aqueous solution is prepared from the product kept at $0^{\circ}$.

Benzene. Thiophene-free reagent benzene (Merck) is allowed to stand over the 2,4-dinitrophenylhydrazine reagent for several days with oceasional shaking in a separatory funnel. After removal of the acid solution, the solvent is then extracted with concentrated sulfuric acid until the acid is colorless. Then the benzene layer is washed with distilled water until the water is neutral. The washed benzene is distilled and the fraction boiling at $77-78^{\circ}$ at $731 \mathrm{~mm} . \mathrm{Hg}$. is collected.

Sodium Bicarbonate. A $5 \%$ solution is prepared from AR grade sodium bicarbonate (Mallinckrodt or Baker \& Adamson) and filtered.

Acetic Acid. A $0.2 \%$ solution is prepared from reagent-grade glacial acetic acid (Baker and Adamson).

Benzyl Alcohol. Benzyl alcohol (Eastman Kodak) is first distilled over 2,4-dinitrophenylhydrazine and then redistilled under reduced pressure.

Color Reagent. A mixture consisting of 1 part of $2.5 \mathrm{~N}$ sodium hydroxide, 2 parts of distilled water, and 7 parts of $95 \%$ ethanol is prepared just before use.

Sodium Hydroxide, $10 \mathrm{~N}$. This is prepared by diluting saturated $\mathrm{NaOH}$ $(18 N)$.

\section{Lloyd's Reagent.}

\section{PROCEDURE}

\section{Blood}

To $7.5 \mathrm{ml}$ sulfosalicylic acid in a $15-\mathrm{ml}$ centrifuge tube is added $1.5 \mathrm{ml}$ of blood sample. The mixture is stirred immediately and thoroughly, using a glass rod. It is centrifuged at $375 \times g$ for $15 \mathrm{~min}$. Five milliliters of the 
supernatant are pipetted into a $15-\mathrm{ml}$ glass-stoppered centrifuge tube. The $\mathrm{pH}$ is adjusted to between 6.0 and 7.0 by using approximately 0.05 $\mathrm{ml}$ of $10 \mathrm{~N}$ sodium hydroxide. Then $0.2 \mathrm{ml}$ of the glucose oxidase mixture is added, and the tube is shaken for an hour on a mechanical shaker at approximately 210 oscillations/min. The tube is then centrifuged for 5 $\min$ at $375 \times g$.

Into each of three $15-\mathrm{ml}$ glass-stoppered centrifuge tubes is pipetted $0.3 \mathrm{ml}$ of the supernatant fluid. The contents of the tubes are acidified with $0.1 \mathrm{ml}$ of concentrated hydrochloric acid. To the remaining supernatant fluid is added sufficient $10 \mathrm{~N}$ sodium hydroxide (approximately $0.16 \mathrm{ml}$ ) to bring the $\mathrm{pH}$ to $13.0-13.5$. The alkaline solution is warmed at $57^{\circ}$ for $5 \mathrm{~min}$, and $0.3 \mathrm{ml}$ of the solution is pipetted into three more centrifuge tubes, each followed with $0.1 \mathrm{ml}$ of concentrated hydrochloric acid. Then $0.3 \mathrm{ml}$ of 2,4-dinitrophenylhydrazine hydrochloride solution is added to each of the six tubes. After mixing, the tubes are placed in a $57^{\circ}$ water bath for $17 \mathrm{hr}$. At the end of the reaction, $0.5 \mathrm{ml}$ pyruvic acid solution is added to all the tubes, and the contents of the tubes are mixed and allowed to react at $57^{\circ}$ for $30 \mathrm{~min}$. The reaction products are extracted by vigorous shaking with $5.5 \mathrm{ml}$ benzene in each tube. The aqueous layer is subsequently removed by a $10-\mathrm{ml}$ syringe with a 5 -in. needle. The exterior of the needle is washed with a little benzene into the extract after cach use. The upper layer is extracted three times with $5 \mathrm{ml}$ of $5 \%$ sodium bicarbonate to remove the derivative of pyruvic acid. The benzene layer was extracted once with $3.6 \mathrm{ml}$ of $0.2 \%$ acetic acid; $0.1 \mathrm{ml}$ benzyl alcohol was added to the benzene layer, and the latter was evaporated to near dryness with an air strean.

To the residue in each tube is added $2 \mathrm{ml}$ of color reagent; the color developed is read at $586 \mathrm{~m} \mu$. The difference between the filtrate without alkali and the filtrate after the alkali treatment gives the color due to dihydroxyacctone. The volume of the color reagent may be changed to yield a suitable absorbance reading. Blanks can be prepared by using water; or, the standard, after treatment with alkali, can be used as a blank. The results have been found to be the same.

A standard solution of dihydroxyacetone of the same concentration range as the samples is prepared and processed with the samples. The linear relationship between absorbance of the final solution and the concentration, as will be seen later, allows one to calculate the concentration of dihydroxyacetone in the samples either with a simple factor or from a straight-line standard curve.

\section{Urine}

The $\mathrm{pH}$ of a fresh urine sample is adjusted to $6.0-7.0$ with $10 \mathrm{~N}$ sodium hydroxide, and treated with Lloyd's reagent. The treated urine is trans- 
ferred into another stoppered centrifuge tube to be shaken with the glucose oxidase mixture as described for blood. One milliliter of the supernatant fluid is pipetted into $5 \mathrm{ml}$ of $10 \%$ metaphosphoric acid in a centrifuge tube, allowed to stand for $30 \mathrm{~min}$, and centrifuged at $375 \times g$ for 15 min. The remaining supernatant fluid is alkalinized as described for blood filtrate, and then $1 \mathrm{ml}$ is pipetted into metaphosphoric acid. The acidic supernatant fluids are processed exactly in the same manner as for acidified blood filtrate. A standard of same concentration range of the samples is run with the latter.

\section{Tissue Homogenate}

The procedure for blood may be applied without modification.

\section{EXPERIMENTAL}

It was observed at the beginning that two factors could render the principle of the proposed procedure inoperative, namely, the glucose present in most samples and an unknown chromogen that gives a red color to the final solution. The formation of an osazone by glucose under the experimental conditions contributes a considerable absorbance reading. However, if the concentration of glucose in the sample is less than 0.3 $\mathrm{mg} / \mathrm{ml}$ the interference becomes insignificant. The problem then simplified itself to that of removal of glucose to below that limit. Attempts were made to correct the interference of the red chromogen by readings taken at different wavclengths without success. The easy destruction of dihydroxyacetone in alkali was then utilized to remove it, and the difference in absorbance readings before and after the alkali treatment would then give the absorbance corresponding to dihydroxyacctonc. The red chromogen was apparently not affected by the alkali treatment.

\section{Glucose Elimination by Oxidase}

The conditions for the effective reduction of the concentration of glucose was established by testing various deproteinizing agents for the blood sample and obscrving the level of glucose after shaking with oxidase. Sulfosalicylic acid was found to be an agent that does not inactivate the enzyme while metaphosphoric acid or trace of barium hydroxide-zinc sulfate docs. Assuming the glucose concentration in an average sample to be below $2.0 \mathrm{mg} / \mathrm{ml}$, the amount of enzyme required to remove this amount of glucose after $\mathbf{3 0}$ min of shaking was established; then, the time of shaking with enzyme was extended to just before the triose level was affected. Since dihydroxyacetone is readily oxidized only in alkaline solution, the removal of glucose by oxidase in an acid medium minimizes the loss due to air oxidation during the shaking. 


\section{Correction for Red Chromogen by Alkali Treatment}

Neutral carbonyl compounds other than dihydroxyacetone, glyceraldehyde, or pyruvaldehyde are obviously present in biological fluids and react with 2,4-dinitrophenylhydrazine to yield a red color (when present) in alcoholic alkali. Numerous attempts were made to correct this interference by reading the final color at various wavelengths. Factors and equations were empirically established to calculate the dihydroxyacetone value, but none were found satisfactory. The difficulty in eliminating this interference, either experimentally or by calculation, led to the removal of the triose with alkali as a solution of the problem. The $\mathrm{pH}$ of dihydroxyacetone solution was adjusted to 13 , and aliquots were removed at 5-min intervals soon after the temperature was raised to, and maintained at $57^{\circ}$. The samples were neutralized immediately, and the remaining triose was determined. It was found that all the triose had been destroyed with $5 \mathrm{~min}$. The amount of red chromogen in blood was generally found to be far less than that in urine.

\section{Linearity of Standard Curve}

The readings at $586 \mathrm{~m} \mu$ in alcoholic alkali of various amounts of 2,4dinitrophenylosazone of dihydroxyacetone equivalent to $0.1,0.2,0.4,0.6$, $0.8,1.0$, and $2.0 \mu \mathrm{g} / \mathrm{ml}$ of the triose were obtained. These readings were found to bear a linear relationship to the concentration of the substance. Solutions containing dihydroxyacetone in $0.01,0.05,0.10$, and $0.25 \mathrm{mg} / \mathrm{ml}$ amounts were analyzed by the complete procedure described; the absorbance readings were found to be proportional to the concentration of the triose.

\section{Reproducibility of the Procedure}

Three blood samples and four urine samples were each divided into six portions; each portion was then analyzed. The standard deviations were calculated by the equation:

$$
\text { S.D. }=\sqrt{\frac{(a-\bar{a})^{2}}{N-2}}
$$

For the blood samples the S.D. werc: $0.6,1.5$, and $1.3 \mu \mathrm{g} / \mathrm{ml}$. For the urine samples: $3.0,2.2,2.2$, and $1.3 \mu \mathrm{g} / \mathrm{ml}$.

\section{Recovery of Added Dihydroxyacetone}

Measured amounts of dihydroxyacetone were added to blood and urine samples. Triplicate analyses that were made of the samples before and after the addition of dihydroxyacetone are shown in Table 1. 
TABLE 1

Recovery of AdDed Dihydroxyacetone

\begin{tabular}{|c|c|c|}
\hline \multirow{2}{*}{ Amount of DHA added ( $\mu \mathrm{g} / \mathrm{ml})$} & \multicolumn{2}{|c|}{ Per cent recovered } \\
\hline & Blood & Urine \\
\hline 10 & $105,100,100$ & $100,90,95$ \\
\hline 20 & $101,100,88$ & $96,91,84$ \\
\hline 30 & $103,99,100$ & $94,88,87$ \\
\hline 100 & $101,89,97$ & 95,89 \\
\hline
\end{tabular}

\section{Interfering Substances}

The partition of osazones between benzene and sodium bicarbonate solution serves to eliminate a large group of interfering substances, namely, the keto acids. Among the neutral carbonyl compounds, acetone does not contribute to the absorbance except in extremely high concentrations. Glyceraldehyde and pyruvaldehyde when present are not distinguishable from dihydroxyacetone. However; if necessary, pyruvaldehyde osazone may be separated from the osazone of dihydroxyacetone, which is identical with that of the glyceraldehyde, by paper chromatography (8). The red chromogen which is the major source of interference has not yet been identified in spite of a large number of neutral carbonyl compounds including methyl ethyl ketone, methyl $n$-propyl ketone, methyl $n$-butyl ketone, methyl $n$-pentyl ketone, formaldehyde, acetaldehyde, propionaldehyde, estrone, and dehydroisoandrosterone that were tested to reproduce the color and $R_{f}$ on paper chromatography.

Monosaccharides tested gave color similar to that of dihydroxyacetone but most of them are removed by alkali treatment. At a concentration level of $200 \mu \mathrm{g} / \mathrm{ml}$, fructose (recrystallized), xylose (Pfanstiehl), arabinose (Matheson), rhamnose (Fisher), galactose (Eastman), and mannose (Fisher) did not interfere. Ribose (Nutritional Biochemical) at 200 $\mu \mathrm{g} / \mathrm{ml}$ gave the equivalent of $1.3 \mu \mathrm{g} / \mathrm{ml}$ dihydroxyacetone, and erythrose (California Corp. for Biochemical Research) gave the equivalent of 18.4 $\mu \mathrm{g} / \mathrm{ml}$.

\section{Preservation of Samples}

Since dihydroxyacetone is relatively labile even in neutral solution, no sample should be kept overnight even in the refrigerator. However, urine samples have been quickly frozen and kept at $-10^{\circ}$ for $24 \mathrm{hr}$ without appreciable change in the results. The blood cells metabolize this substance fairly readily at room temperature; therefore, immediate processing of the sample should be started as soon as possible. 


\section{SUMMARY}

Dihydroxyacetone is reacted with an excess of 2,4-dinitrophenylhydrazine. The excess reagent is removed by the addition of pyruvic acid and followed by partition between benzene and sodium bicarbonate solution. The benzene layer containing the 2,4-dinitrophenylosazone of dihydroxyacetone is evaporated, and the color developed with the addition of alcoholic sodium hydroxide is measured. Glucose, an interfering material in blood or urine, is removed by an oxidase. Other interference is corrected by the removal of dihydroxyacetone with alkali. Effective range of this method is from $5 \mu \mathrm{g}$ dihydroxyacetone. The precision of the method has been measured.

\section{ACKNOWLEDGMENTS}

This work was aided by a grant from the Playtex Park Research Institute. The interest and encouragement of Dr. James $\mathrm{L}$. Wilson is deeply appreciated.

\section{REFERENCES}

1. Rabinowitch, I. M., J. Biol. Chem. 75, 45 (1927).

2. Kermack, W. C., Lambie, C. G., and Ślater, R. H., Biochem. J. 20, 486 (1926).

3. Campbell, W. R., J. Biol. Chem. 67, 59 (1926).

4. McClellan, W. S., J. Biol. Chem. 76, 481 (1928).

5. Silberstein, F., and Rappaport, F., Biochem. Z. 194, 105 (1928).

6. Turner, W. J., Kress, B. H., and Harkison, N. B., J. Biol. Chem. 148, 581 (1943).

7. Strain, H. H., ANd Spoehr, H. J., J. Biol. Chem. 89, 537 (1930).

8. Kostir, J. V., ANd Slavik, K., Coll. Czeck. Chem. Communs. 15, 17 (1950). 